\title{
Review of mapping regional demographic processes using innovative methods and technologies
}

\author{
Sarvar Abdurakhmonov ${ }^{1, *}$,Eshkobul Safarov², Murat Yakubov $^{3}$, and Shavkat Prenov ${ }^{2}$ \\ ${ }^{1}$ Tashkent Institute of Irrigation and Agricultural Mechanization Engineers, Kari-Niyazi \\ str., 39, 100000, Tashkent, Uzbekistan \\ ${ }^{2}$ National University of Uzbekistan, University str., 4, 100174, Tashkent, Uzbekistan \\ ${ }^{3}$ Research Institute of Irrigation and Water Problems, Karasu-4, 11, Tashkent, Uzbekistan
}

\begin{abstract}
Different types of methods in science and technology, such as statistical, cartographic, and satellite materials are being used to describe events and objects. The application of modern GIS technologies in collection and processing of data on regions, demographic processes and events is highly demanding in demographic studies. The main feature of GIS software is to integrate and analyze geographic spatial data, and create map. In this research, it was found that classification and creation of demographic data in regions using GIS software helped to regulate the demographic processes in the regions.
\end{abstract}

\section{Introduction}

In recent years, enormous research and studies have been conducted in all sciences and fields, and unprecedented results have been achieved. In particular, the development of cartography and geo-informatics as a science, technology and industry is no secret to any specialist $[1,2]$. The advent of Geographic Information Systems (GIS) in science has led to the rapid development of the industry with images. The main content of all GIS is an automated cartographic system, a combination of software and computer equipment designed to create and use maps, solve various problems [4, 7]. GIS technologies play very important role in mapping demographic processes using geographic data. An expanded database of cities, towns and villages can be formed when creating digital maps summarizing demographic processes $[5,6]$. With the introduction of innovative technologies, statistical information relevant to the population based on new data on the ground can be received online from local officials and integrated with a geo-data database, which allows to constantly monitoring the dynamics of the population. At present, almost all maps are created using GIS technologies, and interdependence and integration of geoinformatics as well as cartography can be easily seen in a mapping process $[10,13]$. It is stated that the interrelation of cartography and geo-informatics in demographic map can be seen in the following stages [3]: 1) in GIS programs, linking spatial data to a single coordinate system, and using a large-scale topographic maps; 2) entering remote sensing

*Corresponding author: s.abduraxmonov@tiiame.uz; s.n.abduraxmonov@gmail.com 
data and other information (statistical and analytical) used in GIS software into computer memory; 3) Vectorization of data in the form of digital maps to form a component of GIS technology databases; 4) stratification of the thematic structure of spatial objects.

A number of practical tasks related to demographic changes and mapping those ones can be accomplished using GIS software. Furthermore, the application of scientific ideas based on integrated, excellence-based geo-information research in the creation of demographic maps creates opportunities for systematic socio-economic study of the population $[8,9,11]$.

Large-scale electronic digital maps are being developed and used in software programs belonging to the GIS family (ArcGIS, QGIS and MapInfo). The study of demographic processes in regions based on GIS technologies and cartographic methods encompassed the formation and geolocation of databases in mapping, spatial data modeling, integration, improvement of demographic processes and visualization [12-16]. Moreover, modeling of spatial data and geolocation of demographic processes using GIS technologies, development of recommendations for the use of innovative methods and technologies in the creation of demographic maps are the main GIS based step in demographic studies.

\section{Materials and methods}

Karshi city of Uzbekistan was selected as study site in this research. ArcGIS, QGIS, MapInfo programs, questionnaires, regional analysis, and geolocation methods belonging to the family of cartographic, aerospace, statistical, GIS technologies were used in the research process. A systematized structure, Demo GIS $[2,3]$ consisting seven stages was developed towards analyzing demographic situations in the regions and the creations of their digital maps (Fig. 1). Obviously, the formation of this created Demo GIS and map creation system accelerates work process and increases the quality of maps and data accuracy. Noteworthy, the existing mapping stages, which existed before the development of methods and technologies for creating electronic digital maps, involved very complex processes [5].

In this research, the use of existing paper maps as a basis in the creation of digital and electronic maps of some regions does not give the expected result. Therefore, in order to solve the problem, it is necessary to create a cartographic basis. In this case, remote sensing materials were used to create a cartographic basis. The creation of a new cartographic basis provided for the use of images from the landscape spacecraft $[11,13,14]$. This method was useful in improving the quality and accuracy of the cartographic basis. The formation of fundamentally new stages in the process of preparation and copying of original map using the methods and technologies of digital mapping is directly related to the software belonging to the family of geographic information systems.

NDVI was calculated using NDVI = $(\mathrm{IQ}-\mathrm{Q}) /(\mathrm{IQ}+\mathrm{Q})$ the formula $[8,10-12]$. In this case, IQ is the infrared spectrum of the image; $Q$ is the red spectrum of the image. 


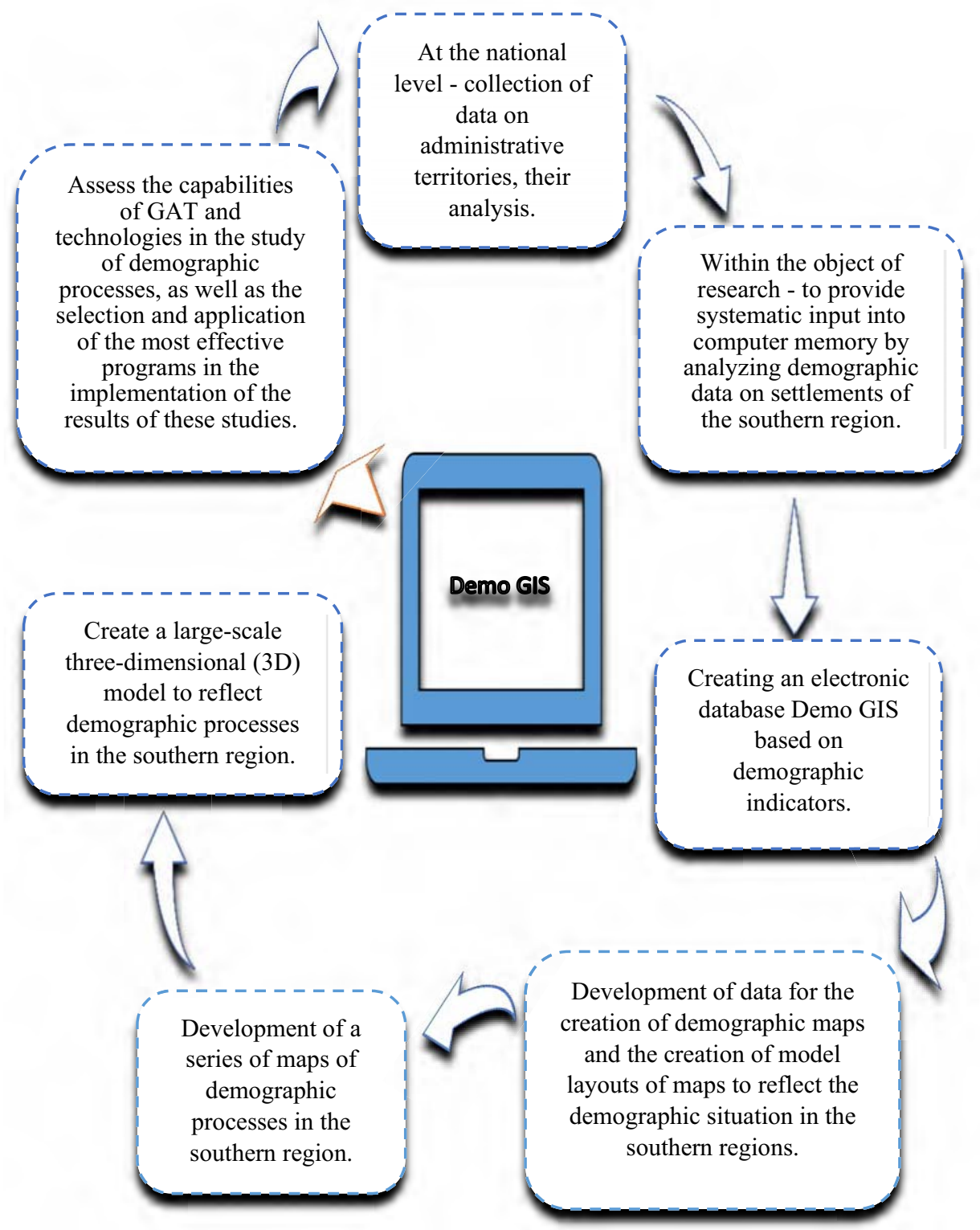

Fig. 1. Demo GIS structure in the creation of demographic maps. 


\section{Results and discussion}

It was found that remote sensing methods provided good opportunities for monitoring and analysis of demographic processes in the regions, as well as for the creation of maps based on the collected results. In this section, analytical studies using several remote sensing methods was reviewed. It was possible to capture high-resolution and continuous (in months, years) satellite images of regions using Google Earth Pro. The main purpose of this would be to track changes in housing over the years. It provided an opportunity to monitor the expansion or contraction of the area occupied by residential areas due to growth and decline in population, and to increase the accuracy of data in population maps created by regions. Another advantage of Google Earth Pro was that it could be easily installed and run even on non-highly configured computer. Obtaining a satellite image of the area using Google Earth Pro was done in the following sequence: once Google Earth Pro was launched, there desired area was found on the globe. This was done by searching or searching the map for the location of the area (Fig. 2). The geographic location program from the selected regions automatically found the desired area. From this, a district or city settlement, where scientific research can be found, would be selected.

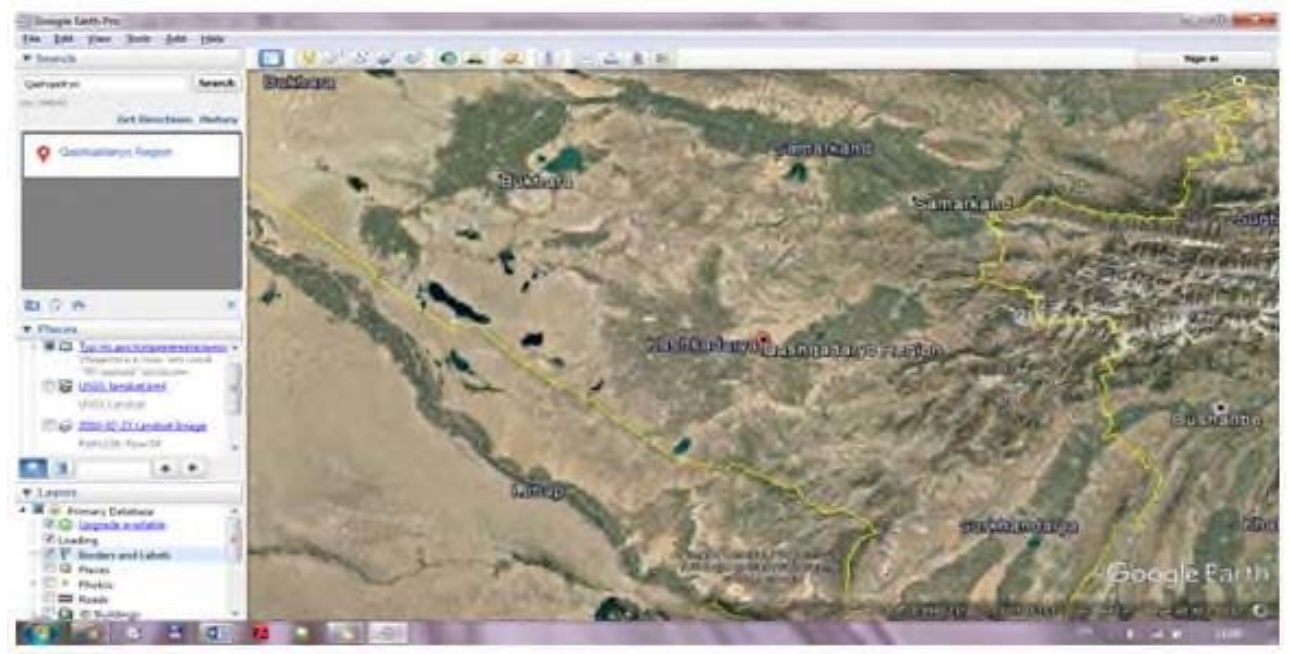

Fig. 2. Search window in Google Earth Pro.

Additionally, images of the area over the years can be seen using the View Historical Images command. By moving the column to the left, images from previous years can be easily seen. The screen save command saves the screen image to the computer's memory (Fig. 3). 


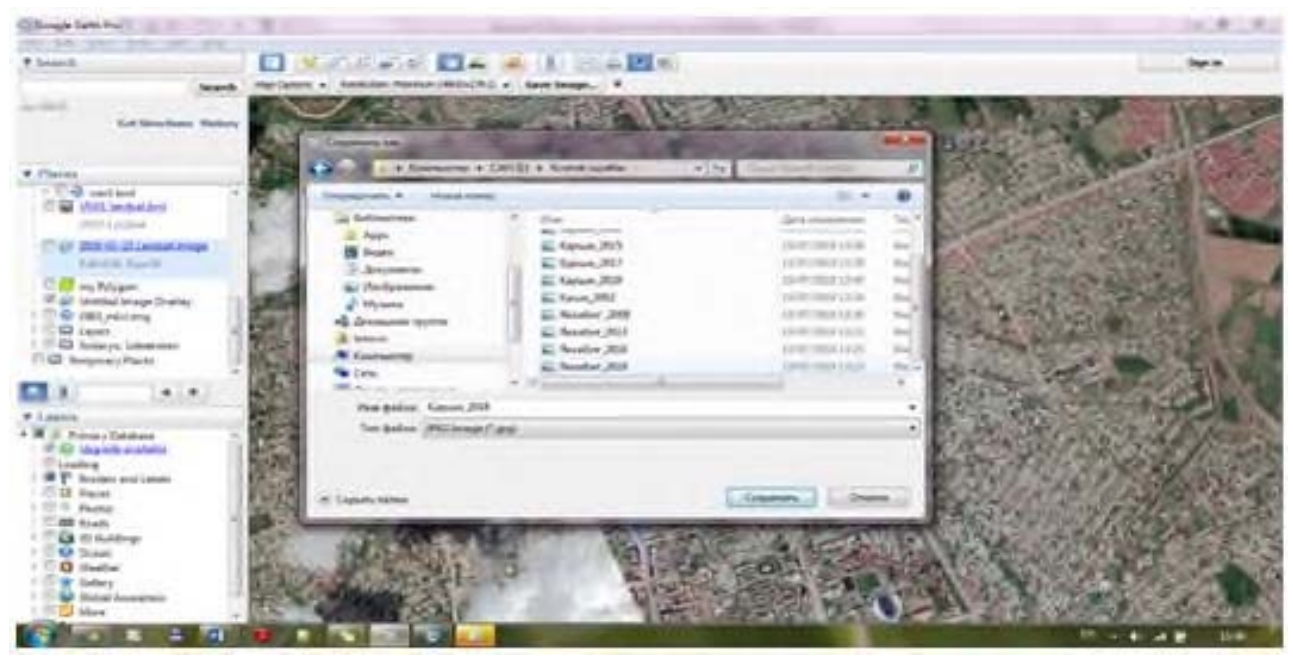

Fig. 3. Saving a spatial image to computer memory.

All possibilities in the processing of remote sensing materials were taken into account. At the local level, monitoring of changes in settlements over the years was also carried out. Remote sensing materials made it possible to analyze changes in local settlements and changes in population and changes in the impact of migration, and it was observed that the location of the population relative to the local relief structure. Spatial images were analyzed and maps of demographic processes in the region were created based on the results obtained (Fig. 4).

In order to monitor demographic processes in the field and to compile maps of demographic processes, as well as to increase the accuracy of the data on the maps, analytical work was carried out in the region. For this, satellite images were downloaded through the Earth Explorer geoportal (Figures 5 and 6) and exported to ArcGIS, and NDVI analysis was performed [15]. 


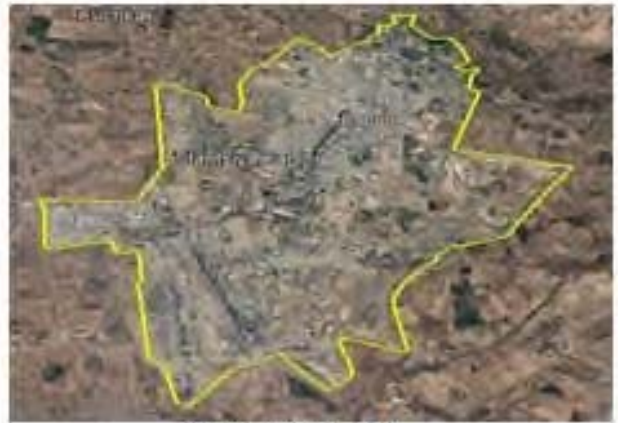

Karshi city 1984

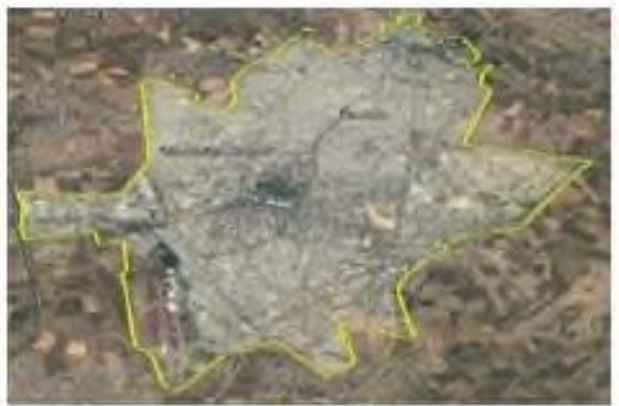

Karshi city 2004

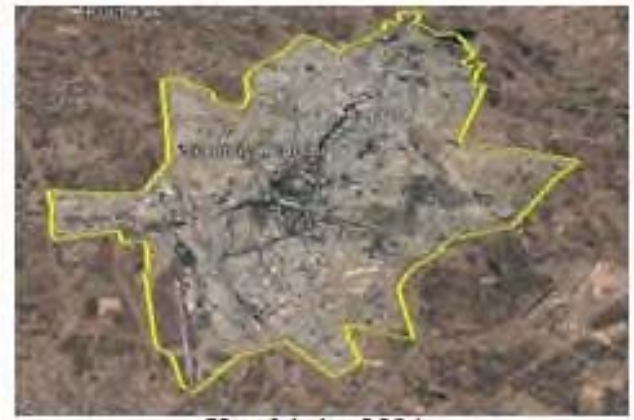

Karshi city 1994

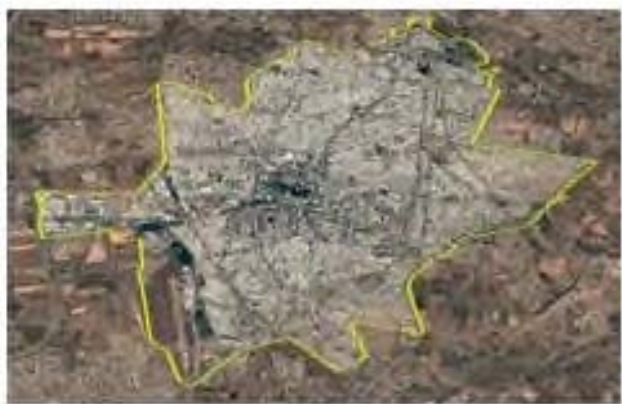

Karshi city 2014

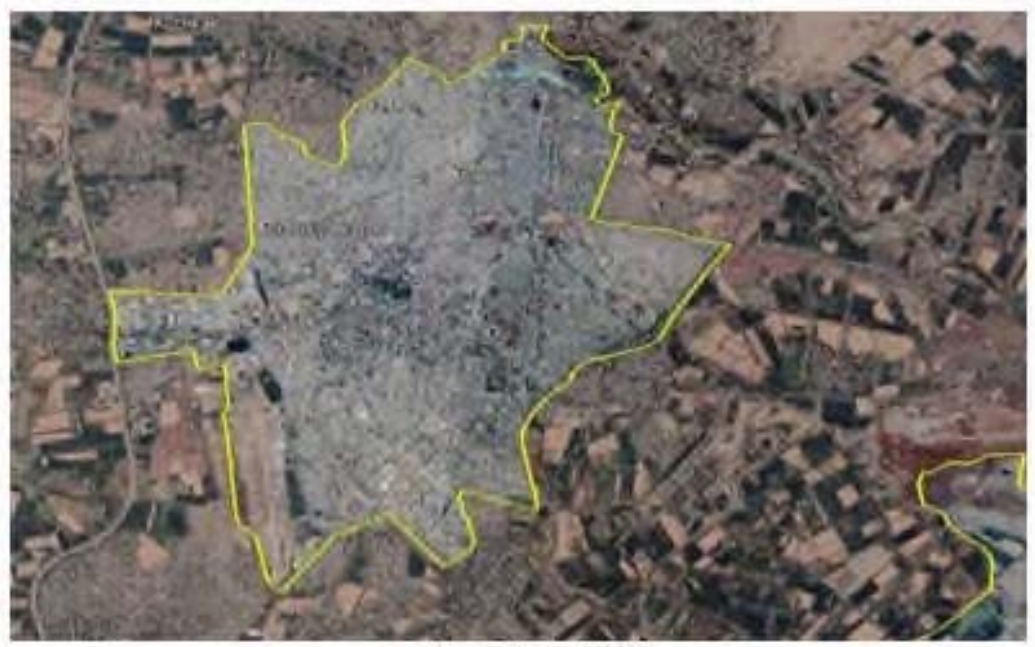

Karshi city 2019

Fig. 4. Change of population settlement in Karshi city during 1984-2019 years. 


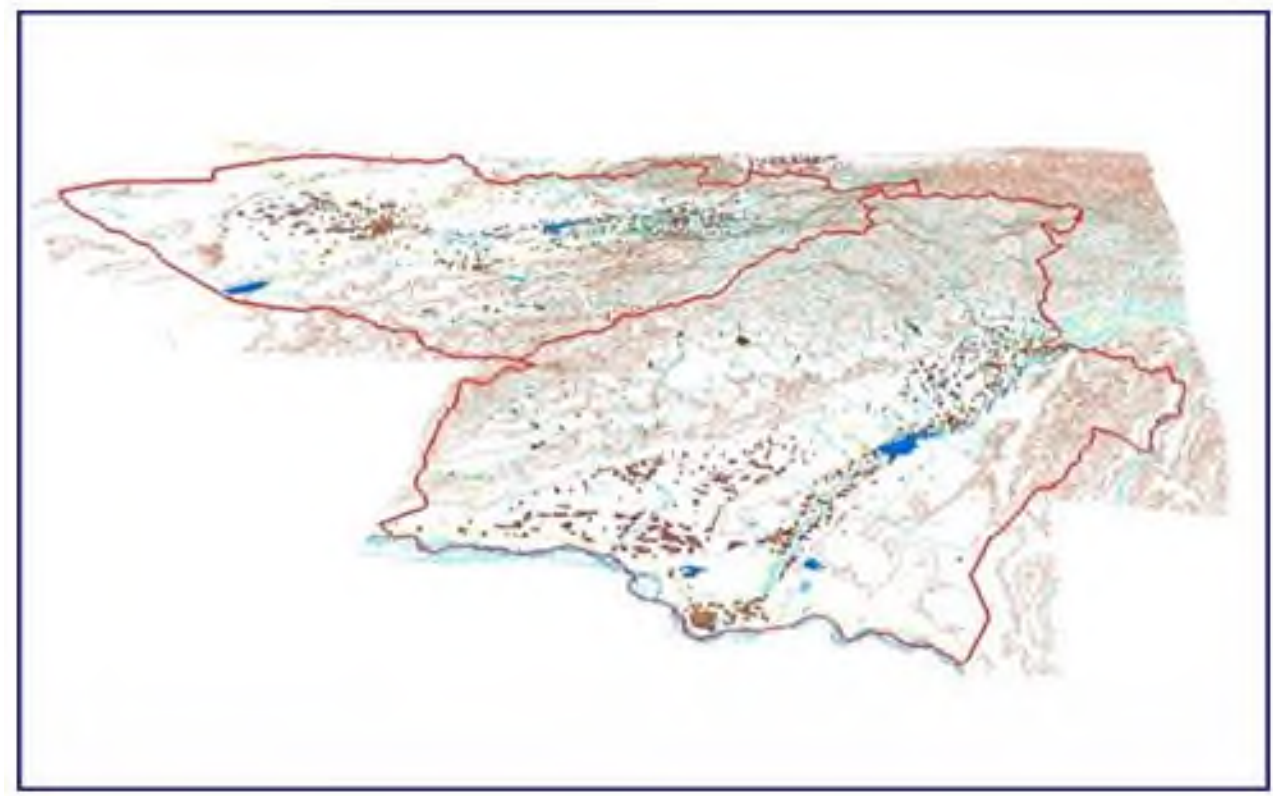

Fig. 5. A visualized 3D model of residential areas in the southern region in 1984-2019.

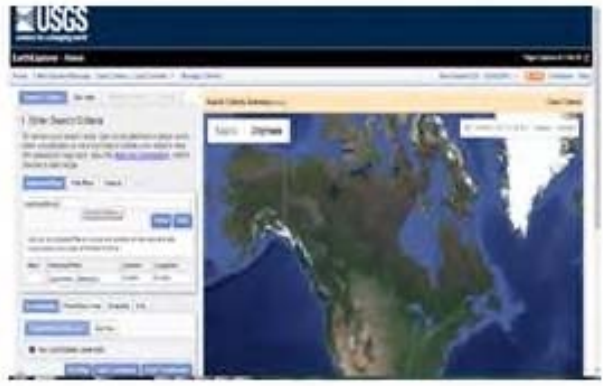

A

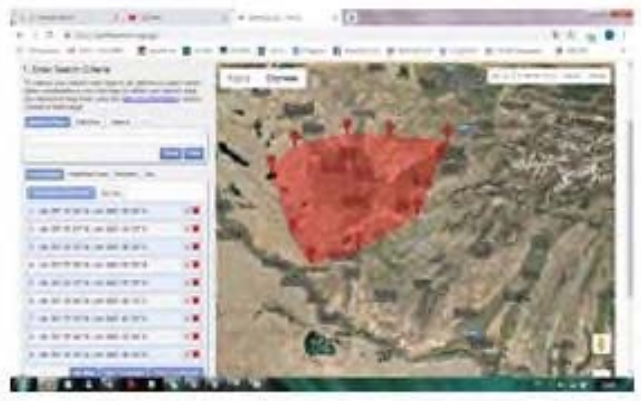

B

Fig. 6. A. Download space images via Earth Explorer geoportal, and B. Search window.

The time period given in the criteria given is given when the image of the selected area is required (Fig. 7A). Once the desired area is selected, a system of space images in the database is selected. For example, images were taken by Landsat or Sentinel satellites. Multi-spectral images taken on the Landsat satellite had a resolution of 30 meters. One pixel in the photo covers an area of 30 meters by 30 meters. In the space image taken on the Sentinel-2 satellite, the resolution is 10 meters by 10 meters. The image of the Sentinel-2 is selected below (Fig. 7B). The next step will be a series of additional criteria. This row includes the cloud cover of the images, the orbital number, the title of the image, and other indicators (Fig. 7C). The result was then searched and images of the area were displayed (Fig. 7C). Additional information about the spatial image can be obtained through metadata (Fig. 7D). If the image is satisfactory, then a download command is issued. The images were exported to ArcGIS software and analysis work was performed. 


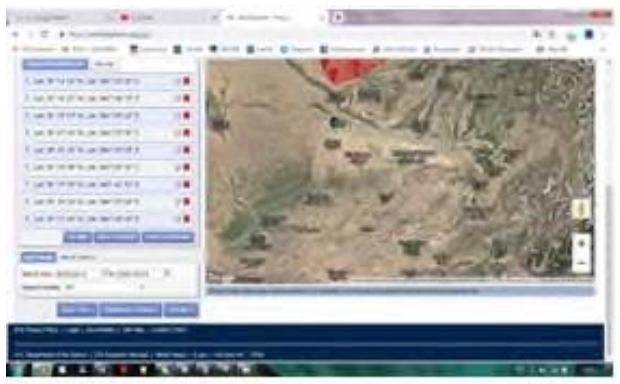

A

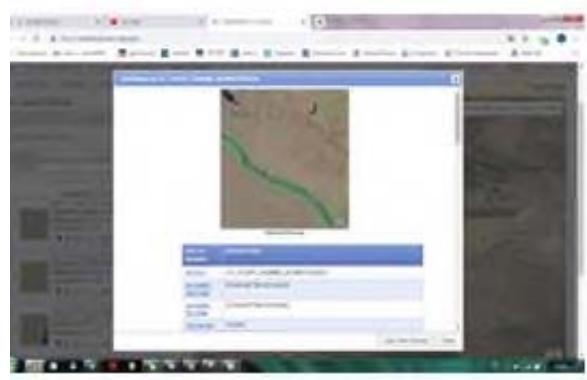

C

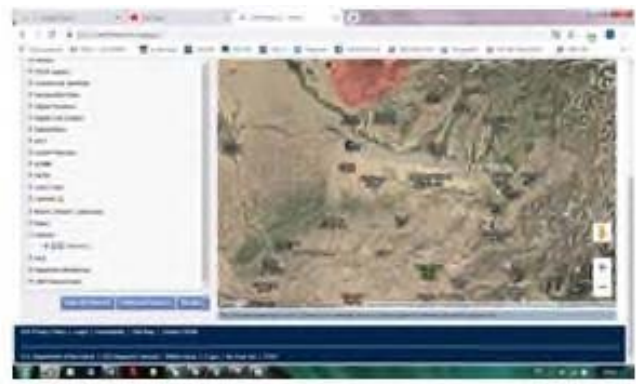

B



D

Fig. 7. A. Selection of a time image of the selected area; B. A satellite image taken on the Sentinel-2 satellite; C. Entering the indicators of the satellite image; and, D. Areas in the spatial image.

Different aspects of dependence on demographic processes in the NDVI analysis were considered. Clearly, the red and infrared spectra of images were used to perform NDVI analysis. Next, the Map Algebra panel was entered into the Spatial Analyst tool through the toolbox and then into the Raster Calculator (Fig. 8).

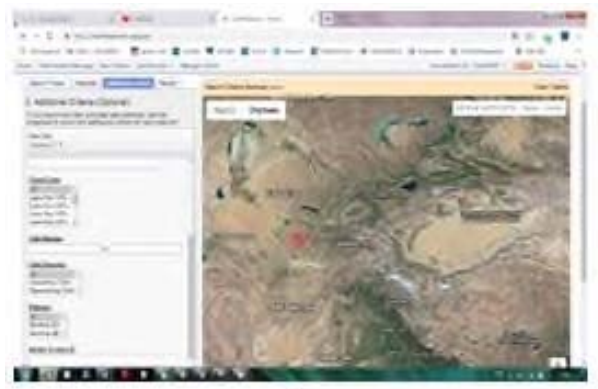

A



B

Fig. 8. A. Adding additional data to the metadata and B. Raster Calculator window.

Typically, the value of the results obtained by analysis varies from 1.0 to -1.0 . The values corresponding to the population points were observed to be in the range of approximately 0.6 to 0.22 . Hence, it has been proved that the observation of changes in periodic time intervals can carry out NDVI analysis in population-related cases and obtain the necessary results on population change (Figures 9 and 10). In the processing of remote sensing materials, the obtained images were initially transformed into a trapezoidal form in the form of a photo scheme, and separate vector layers of common geographical elements 
were formed. Also, topographic maps were prepared as a basis for compiling the first demographic maps of the southern region [6]. Then the quality and topology of the electronic database of the card were controlled. In the next step, the vector layers * sxf. files extension has been converted to ArcGIS *.shp format. In ArcGIS, general geography, hydrography, settlements, roads, borders, relief, industrial and social objects are formed in separate layers and files. The description of the converted files, the symbols in the ArcGIS environment, and the systems of the described objects have changed somewhat.

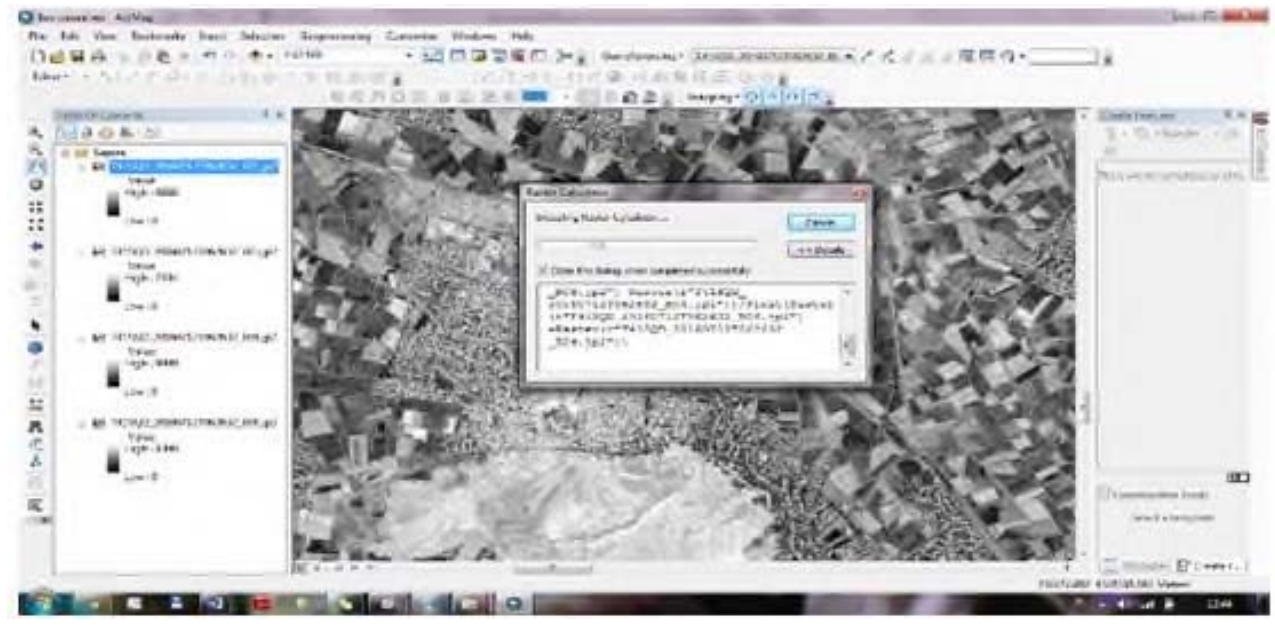

Fig. 9. The process of NDVI analysis.

The development of the thematic content of the map included the process of forming a general geographical content based on natural objects and complexes, as well as a set of conditional symbols and a legend of the map elements. In the production of thematic symbols, the characteristics of objects and complexes on the subject were taken into account. Many objects cannot be displayed due to the scale of the map. Therefore, nonscale symbols were widely used to describe these objects. Cartographic representation methods, dashed symbols were used to represent some elements of natural content. The advantage of the newly created electronic and digital demographic maps was that it was possible to solve the problem of correcting some errors and omissions in the mapping of the obtained research results, and it did not take much time.

Today, the collection of demographic data, the formation of a database is carried out on the basis of ArcGIS, MapInfo, Panorama, GeoDraw, GeoGraph, Atlas GIS, Win GIS, ArcInfo and other programs [8]. In this research used ArcGIS software from the GIS family, which was met the requirements for solving the problems occurred. Above, the mapping work was carried out based on Demo GIS digital demographic mapping technology developed in the second part of the first chapter of the research work. The new cartographic basis created in the program was interconnected to the results through placing the collected statistical data in a central database using the geolocation method. A population map of the southern region was then constructed using cartographic mapping methods (Fig. 10) [10]. 


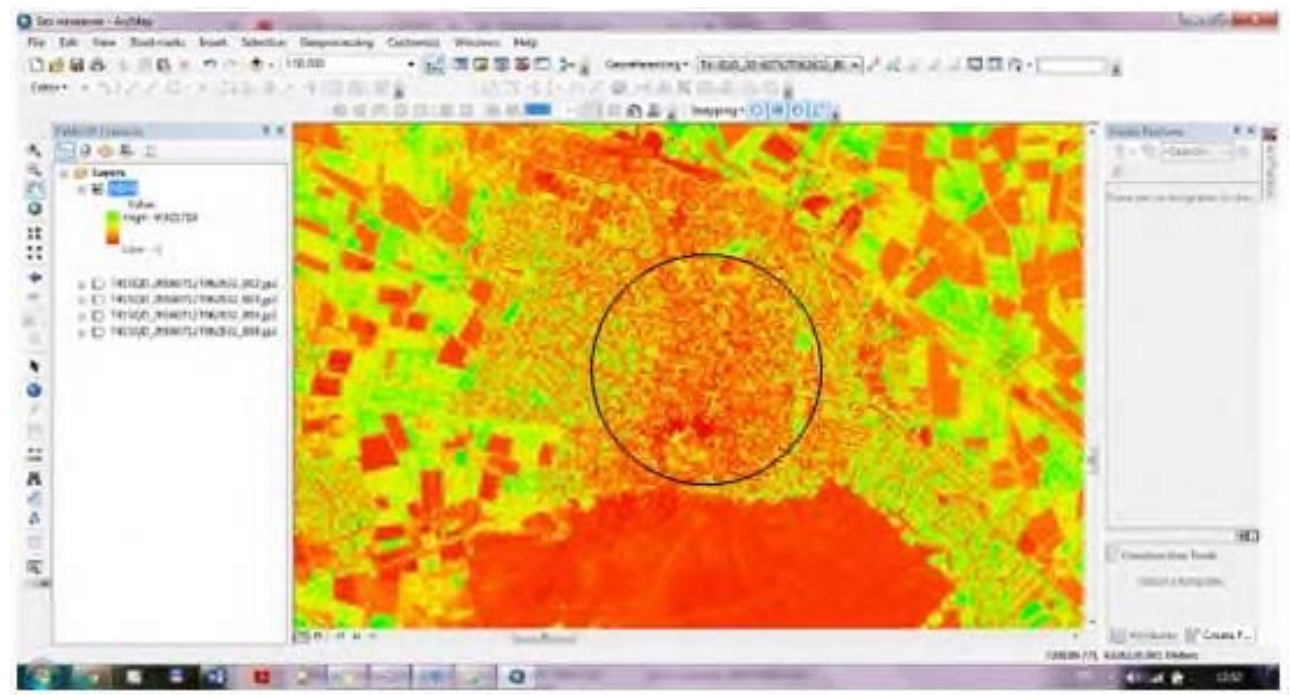

Fig. 10. The result of NDVI analysis.

\section{Conclusions}

The creation of maps, plans, and their processing and data integration through the constant replenishment of databases based on GIS technologies was studied. According to the result of the research, the methodology and technology of creating electronic digital demographic maps were developed. Furthermore, it was found that software belonging to the GIS family as well as selected software tools were compatible in exchanging information with other similar programs.

At the local level, monitoring of changes in settlements over the years was also carried out. Remote sensing materials made it possible to analyze changes in local settlements and changes in population and changes in the impact of migration, and it was observed that the location of the population relative to the local relief structure.

\section{References}

1. S. Abdurakhmanov, M. Atakov, A. Abdullaev, Bulletin of the state agency of the Republic of Uzbekistan "Ergeodeskadastr", 2, 12-13 (2014)

2. Y. Peng, F. Li, N. Xu, R. Kulmatov, K. Gao, G. Wang, Y. Zhang, Y. Qiao, Y. Li, H. Yang, S. Hao, Q. Li, S. Khasanov, Chinese Journal of Eco-Agriculture, 29(2), 312$324(2021)$

3. R. Kulmatov, A. Taylakov, S. Khasanov, Environ. Sci. Pollut. Res., 28(10), $12245-$ 12255 (2021)

4. R. A. Kulmatov, S. A. Adilov, S. Khasanov, IOP Conf. Ser.: Earth Environ. Sci., 614(1), 012149 (2020)

5. N. Teshaev, B. Mamadaliyev, A. Ibragimov, S. Khasanov, InterCarto. InterGIS, 26(3), 324-333 (2020)

6. K. Khakimova, I. Musaev, A. Khamraliev, E3S Web Conf., 227, 02003 (2021) 
7. B. Alikhanov, S. Alikhanova, R. Oymatov, Z. Fayzullaev, A. Pulatov, IOP Conf. Ser.: Mater. Sci. Eng., 883(1), 012088 (2020)

8. I. Musaev, A. Bokiev, M. Botirova, E3S Web Conf., 227, 05004 (2021)

9. N. Sabitova, O. Ruzikulova, I. Aslanov, E3S Web Conf., 227, 03003 (2021)

10. S. Abdurakhmonov, I. Abdurahmanov, D. Murodova, A. Pardaboyev, N. Mirjalolov, A. Djurayev, InterCarto. InterGIS, 26, 319-328 (2020)

11. Z. Mamatkulov, J. Rashidov, G. Eshchanova, M. Berdiev, Z. Abdurakhmonov, IOP Conf. Ser.: Earth Environ. Sci., 614(1), 012086 (2020)

12. I. Aslanov, S. Khasanov, Y. Khudaybergenov, M. Groll, Ch. Opp, F. Li, E. Ramirez Del-Valle, E3S Web Conf., 227, 02005 (2021)

13. M. Lehoczky, Z. Abdurakhmonov, E3S Web Conf., 227, 04001 (2021

14. S. N. Abdurakhmonov, Research of regional demographic processes on the basis of Geoinformation technologies and cartographic techniques (in the example of the southern region of the Republic of Uzbekistan), PhD Dissertation (TIIAME), 185 (2020)

15. S. N. Abdurakhmonov, O. Allanazarov, U. Mukhtorov, N. Mirjalalov, Z. Abdurakhmonov, International Journal of Innovative Technology and Exploring Engineering (IJITEE), 9, 430-435 (2020)

16. A. Jumanov, S. Khasanov, A. Tabayev, G. Goziev, U. Uzbekov, E. Malikov, IOP Conf. Ser.: Earth Environ. Sci., 614(1), 012150 (2020) 